\author{
Р.И. Розина \\ Институт русского языка им. В. В. Виноградова РАН, РГГУ \\ (Россия, Москва) \\ rarozina@yandex.ru
}

\title{
СТРАТЕГИЯ КОНЦЕПТУАЛИЗАЦИИ ПРЕДИКАТНОЙ ЛЕКСИКИ: ГЛАГОЛЫ ПОРЧИ (ЗАГРЯЗНЕНИЯ) - СЕМАНТИКА, СОЧЕТАЕМОСТЬ, АСПЕКТУАЛЬНОЕ ПОВЕДЕНИЕ*
}

Статья посвящена анализу одного из коммуникативно релевантных тематических классов русских глаголов, а именно глаголам загрязнения, и их сопоставлению с английскими глаголами того же тематического класса. Значительное численное превосходство русских глаголов загрязнения над английскими и различие стилистических характеристик - большое количество разговорных глаголов загрязнения в русском языке при их отсутствии в английском - позволяет сделать заключение о том, что загрязнение не является актуальным коммуникативным смыслом в повседневном общении носителей английского языка. Значение загрязнения русских глаголов - peзультат семантической деривации, состоящей в поднятии пресуппозиции основного значения глаголов, принадлежащих другим тематическим классам, до уровня ассерции; у английских глаголов значение загрязнения непроизводно. На основе семантики их основ множество глаголов загрязнения разбиваются на такие подклассы, как глаголы способа загрязнения, глаголы средства загрязнения и глаголы результата. Анализ аспектуального поведения глаголов показывает, что с точки зрения связи между семантикой глаголов и характером видовых пар глаголы результата отличаются от глаголов способа и средства загрязнения. Заключительная часть статьи посвящена проблемам перевода. В английском языке отсутствуют эквиваленты русских разговорных глаголов загрязнения; помимо этого, благодаря развитой в русском языке глагольной префиксации, нескольким русским глаголам загрязнения соответствует один английский. В результате при переводе с русского языка на английский текст становится менее экспрессивным, глаголы загрязнения часто переводятся с помощью глаголов других тематических классов или не переводятся вообще.

Ключевые слова: коммуникативно релевантные смыслы, тематический класс, аспектуальное поведение, глаголы загрязнения, перевод, русский язык, английский язык

* Статья выполнена в рамках проекта «Семантические процессы в сфере местоименной и предикатной лексики: стратегии референции и концептуализации», грант РФФИ № 17-04-00554. 
В силу особенностей российского климата грязь, загрязнение - один из релевантных коммуникативных смыслов ${ }^{1}$. Грязь - весенняя и осенняя распутица изображена на картинах русских художников самых различных периодов, и 19-го в., и современных; слово грязь и связанные с ним встречаются в топонимах, в частности в московских: Садовая-Черногрязская улица - (от названия притока Яузы p. Черногрязки), ул. Балчуг (от тюркск. заимствования в значении 'болото, грязь'), деревня Черная Грязь в Московской области, Грязевка - река Московской области, пограничная с Владимирской областью, Грязи - районный центр в Липецкой области и город и село в Кемеровской области т.п.

Русские глаголы загрязнения - один из самых многочисленных подклассов глаголов порчи объекта. В русском языке глаголов загрязнения около 40 , не считая возвратных глаголов: возюкать, вывалять, вывозить, завозить, загадить, загваздать, загрязнить, закапать, замазать, замарать, замаслить, замурзать, замуслить / замусолить, замусорить, замызгать, запачкать, засалить, заследить, заслюнявить, засуслить, захватать, извозить, изгадить, изгваздать, измазать, измазюкать, испачкать, измызгать, испакостить, мазать 1, мазюкать 3, марать 1, обляпать, обслюнявить, пачкать и др. Среди этих глаголов нет ни одного книжного, все они либо нейтральные, либо разговорные, что свидетельствует о том, что речь о грязи чаще всего идет именно в повседневном общении.

В англоязычной культуре разговоры о грязи и загрязнении явно занимают не такое важное место.. В английском языке намного меньше глаголов загрязнения, чем в русском - их всего 92: daub 'пачкать', 'грязнить (обычно чем-то жидким, краской или грязью)'; dirty 'пачкать'; foul 'пачкать', 'засорять', 'загаживать' - произв. от foul 'гадить'; smear 'пачкать чем-л. жирным или липким', 'мазать'; smirch 'марать', 'пачкать'; smudge ‘пачкать', 'сажать пятна', 'размазывать'; soil 'пачкать', 'грязнить', 'марать', 'покрывать пятнами'; splatter 'забрызгивать (густой субстанцией — краской, грязью, джемом)'; stain 'пятнать', 'покрывать пятнами', 'пачкать') - и среди них ни одного разговорного.

Особенность русских глаголов загрязнения - в том, что за исключением небольшой группы простых (непроизводных) глаголов с самым общим значением загрязнения (грязнить, марать, мазать, пачкать, пятнать), все остальные префиксальные производные от глаголов различной семантики: глаголов перемещения объекта (валять, возить), глаголов прикосновения (лапать, хватать), глаголов покрытия объекта чем-либо (маслить, слюнить). Исключение представляют глаголы загваздать / изгваздать 'сильно загрязнить' и замызгать 'истрепать, испачкать': мотивирующие их глаголы в современном русском языке не употребля-

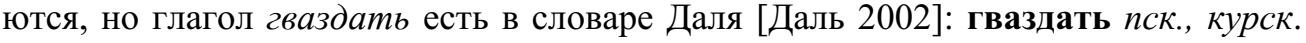
марать, мазать, грязнить, пачкать, гадить, от гвазда 'грязь'), а глагол мызгать

${ }^{1}$ О коммуникативно значимых (релевантных) смыслах и семантических полях см. статьи [Крысин 2012], [Розина 2015].

${ }^{2}$ Список глаголов приводится по словарю [Collins Thesaurus 2018]. 
в словарях Ушакова [Ушаков 1935-1940, т. 2]: мызгать (nрост.) пачкать, мять, трепать (платье, белье) и Ефремовой [Ефремова 2000]: мызгать разг.-сниж. Пачкать, портить небрежной ноской, трепать (обычно одежду).

Глаголов разных тематических классов, мотивирующих русские глаголы загрязнения, около 20, и такая огромная разница между числом мотивирующих глаголов и числом префиксальных производных объясняется тем, что их соотношение имеет характер пучка: от одного мотивирующего глагола образуется несколько префиксальных глаголов загрязнения, например:

\begin{tabular}{|c|c|c|c|c|}
\hline \multirow{3}{*}{ возить } & вывозить & & & замазать \\
\hline & завозить & или & мазать & вылмазать \\
\hline & извозить & & & $\begin{array}{l}\text { измазать } \\
\text { перемазать }\end{array}$ \\
\hline
\end{tabular}

Каким образом у префиксального производного глагола, мотивированного глаголом, не принадлежащим тематическому классу глаголов загрязнения, возникает значение загрязнения? Рассмотрим несколько примеров.

1. Глагол загрязнения мотивирован глаголом перемещения объекта:

Валять - вывалять / извалять.

Только за один съемочный день звезду три раза валяли в снегу (Комсомольская правда, 15.03.2007);

Она [собака] мотала и валяла Софочку по земле, не разжимая челюстей (Комсомольская правда, 07.11.2009).

Толкование:

Ассерция: Субъект ворочал Объект с боку на бок, катал, волочил по поверхности или в массе.

Следствие: частицы поверхности или массы приходили в контакт с поверхностью Объекта.

В толковании производных префиксальных глаголов вывалять и извалять компонент толкования, описывающий перемещение Объекта, становится пресуппозицией, а следствие поднимается до уровня ассерции:

вывалять / извалять

В Санкт-Петербурге курьер известной кондитерки “Невские берега" в прямом смысле сначала вывалял пирожные в грязном снегу с землёй, а потом обратно их расфасовал (VistaNews, 22.02.2017).

Ударная волна погасила костер, разметала, изваляла в песке контуженную компанию, а заодно и других, поблизости отдыхающих (Комсомольская правда, 08.05.2001)

Толкование:

Пресуппозиция: Субъект перемещал Объект по поверхности / в массе

Ассерция: частицы массы пришли в контакт с поверхностью Объекта;

Объект покрыт частицами массы;

Следствие: тем самым Объекту нанесен ущерб: Объект грязный. 
При этом должно быть соблюдено еще одно условие: масса, в которой перемещают Объект, должна быть 'плохой', неподходящей к данному Объекту: это пыль, грязь смола, перья. Если масса, в которой перемещают Объект, 'хорошая', Объект грязным не становится, ср.:

Сформированные шарики вывалять в какао, кокосовой стружке или молотых орехах (рецепт пирожного «Картошка» из блогов, 2018).

Между тем, если в какао вывалять рукав, он станет грязным.

2. Глагол загрязнения мотивирован глаголом прикосновения хватать.

Предметы без спроса не хватай руками своими погаными... (В. Пронин. Банда 8) Толкование:

Ассерция: Субъект приводит руки в плотный контакт с Объектом.

Следствие: руки Субъекта оставляют следы на поверхности Объекта

Захватать

Толкование

Пресуппозиция: Субъект привел руки в плотный контакт с поверхностью Объекта

Ассерция: на поверхности Объекта следы рук Субъекта.

Следствие: Тем самым Объекту нанесен ущерб: Объект грязный.

Этот глагол демонстрирует еще одно важное ограничение на сочетаемость: поверхность, с которой происходит контакт, должна обладать определенным свойством: на ней должны быть видны следы пальцев - т. е. она должна быть гладкой и блестящей или абсолютно чистой. По данным НКРЯ, захватанными могут быть блестящие поверхности стеклянные (стакан, очки), полированные (крышка рояля) и различные предметы из ткани (полотенце), дерева (ручка молотка), бумаги (деньги).

Очень яркий пример - глагол ляпать 'ударять', в этом значении в современном русском языке не использующийся. Его префиксальные дериваты, заляпать и обляnaть имеют значение 'запачкать чем-л. жидким'. Понятно, что для того, чтобы такое значение появилось, нужно, чтобы у глагола ляпать было следствие 'летят брызги', а это, в свою очередь, требует, чтобы у глагола ляпать был подходящий Объект лужа, канава , заполненная грязью и т. п. И действительно, в других славянских языках находим соответствующие русск. ляпать глаголы, у которых есть значение 'ударять ногами по воде или по грязи': укр. ляпати'шлёпать', с.-хорв. 'шлёпать по грязи'з .

С точки зрения семантики основ глаголы загрязнения можно разделить на три группы.

1. Непроизводные глаголы с общим значением 'пачкать' (ни способ, которым пачкают что-либо, ни субстанцию, которой пачкают, глагол не описывает): грязнить, марать, мазать, пачкать, пятнать. Назовем эти глаголы глаголами результата.

3 Автору данной статьи встречалось также диалектное значение глагола обляпывать 'ударами лопаты укреплять боковые стороны грядки'. 
2. Префиксальные дериваты глаголов различной семантики, описывающих способ воздействия на Объект. Назовем их глаголами способа загрязнения : вblвалять, извалять, вывозить, извозить, завозюкать (сниж.), извозюкать (сниж.), закаnать, обкапать, залапать, заляпать, обмазать, перемазать, замазюкать (сниж.), измазюкать (сниж.), обмусолить, замусолить, наследить, заследить, захватать.

\begin{tabular}{|l|l|}
\hline \multicolumn{1}{|c|}{$\begin{array}{c}\text { Непроизводный } \\
\text { глагол }\end{array}$} & \multicolumn{1}{c|}{$\begin{array}{c}\text { Префиксальный } \\
\text { дериват - глагол } \\
\text { способа загрязнения }\end{array}$} \\
\hline \multirow{3}{*}{ валять } & вывалять \\
\cline { 2 - 2 } возить & извалять \\
\hline \multirow{3}{*}{ возюкать (сниж.) } & завозить \\
\cline { 2 - 2 } & извозить \\
\hline \multirow{2}{*}{ капать } & завозюкать \\
\hline \multirow{2}{*}{ лапать } & закапать \\
\hline \multirow{2}{*}{ ляпать } & обкапать \\
\hline
\end{tabular}

\begin{tabular}{|c|c|}
\hline $\begin{array}{c}\text { Непроизводный } \\
\text { глагол }\end{array}$ & $\begin{array}{c}\text { Префиксальный } \\
\text { дериват - глагол } \\
\text { способа загрязнения }\end{array}$ \\
\hline \multirow{4}{*}{ мазать } & замазать \\
\hline & измазать \\
\hline & обмазать \\
\hline & перемазать \\
\hline \multirow{2}{*}{ мазюкать } & измазюкать \\
\hline & замазюкать \\
\hline \multirow{2}{*}{ муслить / мусолить } & замуслить / замусолить \\
\hline & обмусолить \\
\hline \multirow{2}{*}{ следить } & заследить \\
\hline & наследить \\
\hline - & изгваздать \\
\hline хватать & захватать \\
\hline
\end{tabular}

3. Третья группа - приставочные дериваты глаголов, указывающих на перемещение какой-либо субстанции на поверхность Объекта. Поскольку основа глагола называет эту субстанцию, назовем эту группу глаголов глаголами средства загрязнения.

\begin{tabular}{|l|l|}
\hline $\begin{array}{c}\text { Непроизводный глагол } \\
\text { перемещения массы } \\
\text { на поверхность объекта }\end{array}$ & $\begin{array}{c}\text { Приставочный } \\
\text { дериват - } \\
\text { глагол средства } \\
\text { загрязнения }\end{array}$ \\
\hline $\begin{array}{l}\text { *газдать (утерян; } \\
\text { от гвазда ‘грязь') }\end{array}$ & загваздать \\
\hline маслить & замаслить \\
\hline мусорить & замусорить \\
\hline
\end{tabular}

\begin{tabular}{|l|l|}
\hline $\begin{array}{c}\text { Непроизводный глагол } \\
\text { перемещения массы } \\
\text { на поверхность объекта }\end{array}$ & $\begin{array}{c}\text { Приставочный } \\
\text { дериват - } \\
\text { глагол средства } \\
\text { загрязнения }\end{array}$ \\
\hline *салить & засалить \\
\hline \multirow{4}{*}{ слюнить } & заслюнить \\
\cline { 2 - 2 } & обслюнить \\
\cline { 2 - 2 } & обслюнявить \\
\hline
\end{tabular}

Обращает на себя внимание различие префиксов, использующихся в каждой группе глаголов. В группе глаголов способа используется 4 различных префикса: за- , из-, об- , вbl-. В группе глаголов средства - всего 2, за- и об-.

Рассмотрим теперь аспектуальное поведение глаголов каждой группы.

\section{Глаголы результата}

Глаголы первой группы (глаголы результата) могут образовывать видовые пары с префиксальными производными, например, пачкать - испачкать, и пачкать запачкать. Обе пары проходят тест Маслова — [Маслов 1984]: глагол совершенного вида позволяет замену на глагол несов. в контексте настоящего исторического и на глагол несов. в тривиальном значении (в значении повторяющегося действия): 
Он испачкал/ запачкал куртку сажей.

Он пачкает куртку сажей и уходит.

Каждый вечер у костра он пачкает куртку сажей.

Однако кроме этих двух глаголов совершенного вида, являющихся его видовыми парами, пачкать мотивирует еще один префиксальный глагол совершенного вида, не являющийся его видовой парой, перепачкать. Приставка пере- вносит в значение глагола семантический признак 'весь' или 'сильно', и глагол перепачкать не может быть заменен глаголом пачкать в контекстах Маслова, ср.:

Они полезли к нему целоваться и перепачкали его сгущенкой (Г. Галахова. Легкий кораблик - капустный листок). $\neq$

Они лезут к нему целоваться и пачкают его сгущенкой.

Всякий раз они лезут к нему целоваться и пачкают его сгущенкой.

Соотношение глагола пачкать с префиксальными производными поэтому выглядит следующим образом:

\begin{tabular}{|c|l|l|}
\hline \multicolumn{1}{|c|}{ Глагол } & \multicolumn{1}{|c|}{ Префиксальный дериват — видовая пара } & \multicolumn{1}{|c}{$\begin{array}{c}\text { Префиксальный дериват другой } \\
\text { семантики }\end{array}$} \\
\hline \multirow{4}{*}{ пачкать } & испачкать & \\
\cline { 2 - 3 } & запачкать & выпачкать \\
\cline { 2 - 3 } & & обпачкать \\
\cline { 2 - 3 } & & перепачкать \\
\cline { 2 - 3 } & &
\end{tabular}

Однако у префиксальных производных есть свои видовые пары, которые образованы суффиксацией: выпачкать - выпачкивать. Возникает следующая картина:

\begin{tabular}{|c|l|l|l|}
\hline $\begin{array}{c}\text { Глагол } \\
\text { результата }\end{array}$ & $\begin{array}{c}\text { префиксальный дериват - } \\
\text { видовая пара }\end{array}$ & $\begin{array}{l}\text { Префиксальный дериват } \\
\text { другой семантики }\end{array}$ & \multicolumn{1}{c|}{$\begin{array}{c}\text { Видовая пара - } \\
\text { суффиксальный дериват }\end{array}$} \\
\hline \multirow{5}{*}{ пачкать } & испачкать & & \\
\cline { 2 - 4 } & запачкать & & \\
\cline { 2 - 4 } & & выпачкать & выпачкивать \\
\cline { 2 - 4 } & & обпачкать & обпачкивать \\
\cline { 2 - 4 } & & перепачкать & перепачкивать \\
\hline
\end{tabular}

Так же устроены другие глаголы этой группы, кроме пятнать, у которого нет префиксального производного, не являющегося его видовой парой.

\begin{tabular}{|l|l|l|l|l|}
\hline $\begin{array}{c}\text { Глагол } \\
\text { результата }\end{array}$ & $\begin{array}{c}\text { видовая пара - } \\
\text { префиксальный } \\
\text { дериват }\end{array}$ & $\begin{array}{c}\text { Видовая пара - } \\
\text { суффиксальный } \\
\text { дериват }\end{array}$ & $\begin{array}{c}\text { Префиксальный } \\
\text { дериват другой } \\
\text { семантики }\end{array}$ & $\begin{array}{c}\text { Видовая пара - } \\
\text { суффиксальный } \\
\text { дериват }\end{array}$ \\
\hline \multirow{3}{*}{ гадить } & загадить & загаживать & & \\
\cline { 2 - 5 } & & & изгадить & изгаживать \\
\cline { 2 - 5 } & & & обгадить & обгаживать \\
\hline \multirow{2}{*}{ грязнить } & загрязнить & & & \\
\cline { 2 - 5 } & замазать & замазывать & измазать & измазывать \\
\cline { 2 - 5 } & & & перемазать & перемазывать \\
\cline { 2 - 5 } & & & вымазать & вымазывать \\
\cline { 2 - 5 }
\end{tabular}




\begin{tabular}{|l|l|l|l|l|}
\hline $\begin{array}{c}\text { Глагол } \\
\text { результата }\end{array}$ & $\begin{array}{c}\text { видовая пара - } \\
\text { префиксальный } \\
\text { дериват }\end{array}$ & $\begin{array}{c}\text { Видовая пара - } \\
\text { суффиксальный } \\
\text { дериват }\end{array}$ & $\begin{array}{c}\text { Префиксальный } \\
\text { дериват другой } \\
\text { семантики }\end{array}$ & $\begin{array}{c}\text { Видовая пара - } \\
\text { суффиксальный } \\
\text { дериват }\end{array}$ \\
\hline \multirow{2}{*}{ марать } & замарать & замарывать & & измарывать \\
\cline { 2 - 5 } пятнать & запятнать & запятнывать & & \\
\hline
\end{tabular}

Таким образом, в рамках глаголов результата есть три типа видовых пар:

а) тип грязнить - загрязнить: глагол несов. - префиксальный глагол сов.;

б) тип измазать - измазывать: префиксальный глагол сов. - глагол несов., образованный суффиксацией;

в) кроме того, встречаются видовые тройки: замазать - мазать и замазывать и замарать - марать и замарывать.

\section{Глаголы способа загрязнения}

Посмотрим теперь, как себя ведут глаголы способа. Все глаголы способа образованные от непроизводных глаголов описывающих различные способы воздействия на объект, - префиксальные дериваты совершенного вида. Их видовые пары образованы с помощью суффиксации, например, вываливать от выввалять. Глагол ляпать 'ударить' мотивирует два префиксальных глагола загрязнения: заляпать и обляпать, у каждого из которых есть видовая пара, образованная с помощью суффиксации: заляпывать и обляпывать. Часть этих суффиксальных имперфективов факультативна. В целом, возникает следующая картина (0 в таблице стоит в тех случаях, когда имперфектив возможен, но судя по отсутствию примеров в Национальном корпусе, не используется):

\begin{tabular}{|c|c|c|c|}
\hline $\begin{array}{c}\text { Мотивирующий } \\
\text { глагол воздействия }\end{array}$ & $\begin{array}{l}\text { Префиксальный дериват - } \\
\text { глагол способа загрязнения }\end{array}$ & $\begin{array}{c}\text { Суффиксальный имперфектив - } \\
\text { видовая пара }\end{array}$ & $\begin{array}{c}\text { Наличие } \\
\text { в НКРЯ }\end{array}$ \\
\hline \multirow{2}{*}{ валять } & вывалять & вываливать & + \\
\hline & извалять & - & \\
\hline \multirow{3}{*}{ возить } & вы́возить & - & \\
\hline & завозить & - & \\
\hline & извозить & - & \\
\hline \multirow{2}{*}{ возюкать (сниж.) } & завозюкать & завозюкивать & 0 \\
\hline & извозюкать & извозюкивать & 0 \\
\hline лапать & залапать & залапывать & 0 \\
\hline \multirow{2}{*}{ ляпать } & заляпать & заляпывать & + \\
\hline & обляпать & обляпывать & 0 \\
\hline \multirow{2}{*}{ мазюкать } & измазюкать & измазюкивать & 0 \\
\hline & замазюкать & замазюкивать & 0 \\
\hline \multirow{2}{*}{ муслить / мусолить } & замуслить / замусолить & замусливать / замусоливать & + \\
\hline & обмусолить & обмусоливать & 0 \\
\hline \multirow{2}{*}{ следить } & заследить & & 0 \\
\hline & наследить & - & \\
\hline - & изгваздать & изгваздывать & 0 \\
\hline хватать & захватать & захватывать & 0 \\
\hline
\end{tabular}


Из таблицы видно, что в рамках глаголов способа, в отличие от глаголов результата, встречаются только видовые пары, образованные суффиксацией, например залапать - залапьвать; замусолить - замусоливать. При этом отсутствие примеров в Национальном корпусе русского языка говорит о том, что во многих случаях глагол несов. либо потенциальный либо очень малоупотребительный. Реальных видовых пар оказывается всего три: вывалять - вываливать, заляпать заляпьвать и замусолить - замусоливать.

\section{Глаголы средства}

\begin{tabular}{|l|l|l|c|}
\hline $\begin{array}{c}\text { Мотивирующий глагол перемещения } \\
\text { массы }\end{array}$ & $\begin{array}{l}\text { Префиксальный дериват - } \\
\text { глагол загрязнения }\end{array}$ & $\begin{array}{c}\text { Суффиксальный } \\
\text { имперфектив }\end{array}$ & $\begin{array}{c}\text { Наличие } \\
\text { в НКРя }\end{array}$ \\
\hline *гваздать (утерян; от гвазда 'грязь') & загваздать & \multicolumn{1}{|c|}{-} & - \\
\hline \multirow{2}{*}{ капать } & закапать & закапывать & 0 \\
\cline { 2 - 4 } & обкапать & обкапывать & 0 \\
\hline \multirow{2}{*}{ маслить } & замаслить & замасливать & + \\
\hline \multirow{2}{*}{ мусорить } & замусорить & замусоривать & + \\
\cline { 2 - 4 } & засалить & засаливать & + \\
\hline \multirow{2}{*}{ слюнить } & заслюнить & - & - \\
\cline { 2 - 4 } & обслюнить & - & - \\
\hline \multirow{2}{*}{ слюнявить } & заслюнявить & заслюнявливать & 0 \\
\cline { 2 - 4 } & обслюнявить & обслюнявливать & + \\
\hline
\end{tabular}

Итак, для глаголов средства характерны только видовые пары, в которых глагол несов. образован с помощью суффиксации, причем несколько глаголов несов. только потенциально возможны.

В целом, аспектуальное поведение разных групп глаголов загрязнения выглядит следующим образом:

\begin{tabular}{|l|c|c|c|}
\hline & \multicolumn{3}{|c|}{ Характер аспектуального поведения } \\
\hline & \multicolumn{2}{|c|}{ Тип видовой пары } & $\begin{array}{c}\text { Видовая } \\
\text { тройка }\end{array}$ \\
\hline Группа глаголов & $\begin{array}{l}\text { Непроизводный глагол не- } \\
\text { сов- глагол сов., образован- } \\
\text { ный префиксацией приставоч- } \\
\text { ный дериват }\end{array}$ & $\begin{array}{l}\text { Префиксальный глагол сов - } \\
\text { глагол несов., образованный } \\
\text { суффиксацией дериват }\end{array}$ & \\
\hline Глаголы результата & + & + & + \\
\hline Глаголы способа & - & + & - \\
\hline Глаголы средства & - & + & - \\
\hline
\end{tabular}

Судя по этой картине, четкая связь между семантикой и аспектуальным поведением прослеживается у глаголов результата. Они противопоставлены глаголам способа и средства, имеющим сходные аспектуальные характеристики. 


\section{Проблемы перевода}

Разбиение английских глаголов загрязнения на группы примерно такое же, как разбиение русских: глаголы с общим значением загрязнения (глаголы результата): dirty, foul, smirch, soil (всего 4); глаголы, указывающие на характер вещества которое попадает на поверхность объекта, - как правило, густого или жирного (глаголы средства): daub 'пачкать', 'грязнить (обычно чем-то жидким, краской или грязью)', smear 'пачкать чем-л. жирным или липким', splatter 'забрызгивать (густой субстанцией — краской, грязью, джемом)'; (всего 3); глаголы, указывающие на способ помещения пачкающего вещества на поверхность объекта: smudge 'пачкать', 'сажать пятна', 'размазывать'; splatter забрызгивать (обычно чем-л. густым: краской, грязью, джемом)'; stain 'пятнать', 'покрывать пятнами', 'мазать' (всего 3). Между тем количественное наполнение групп английских и русских глаголов резко различается:

\begin{tabular}{|l|c|c|}
\hline \multicolumn{1}{|c|}{ Семантическая группа глаголов } & Русские глаголы & Английские глаголы \\
\hline Глаголы результата & 20 & 4 \\
\hline Глаголы способа воздействия на объект & 19 & - \\
\hline $\begin{array}{l}\text { Глаголы способа перенесения вещества на поверх- } \\
\text { ность объекта }\end{array}$ & - & 3 \\
\hline Глаголы средства & 7 & 3 \\
\hline
\end{tabular}

Такое расхождение в количестве глаголов каждой группы и, в частности, большое количество специализированных глаголов, описывающих частные характеристики действия загрязнения в русском языке, неизбежно должно вызывать трудности при переводе. Действительно, переводчик иногда не находит эквивалента, и глагол или причастие, имеющие значение загрязнения, в английском переводе просто опускаются, ср. ${ }^{4}$ :

Весь измазанный в мазуте машинист быстро поставил масленку (Н. Островский. Как закалялась сталь) - The man dropped his oil can [букв.] 'Мужчина поставил масленку'.

Глагол загрязнения может быть заменен глаголом другого семантического класса, и значение загрязнения просто теряется, ср.:

[Вдова] была замарана мукой (И. Ильф, Е. Петров. Двенадцать стульев) 一 [Тhе widow] was covered with flour [букв.] 'Вдова была покрыта мукой'.

Платок был густо замаран кровью (Ф. Достоевский. Братья Карамазовы)

The handkerchief was soaked with blood [букв.] 'Платок был пропитан кровью'.

Еще одна возможность - заменить глагол или причастие атрибутивным словосочетанием, например:.

В маленьком грязном нумере, заплеванном по раскраменным панно стен... (Л. Толстой. Анна Каренина)

${ }^{4}$ Все примеры переводов приводятся по параллельному корпусу Национального корпуса русского языка. 
In a little dirty room with the painted panels of its walls filthy with spittle (Constance Garnett).

Напротив, при переводе с английского языка на русский один и тот же английский глагол получает разные эквиваленты в разных контекстах, ср.:

\begin{tabular}{|l|l|l|l|}
\hline $\begin{array}{c}\text { Английский глагол } \\
\text { загрязнения }\end{array}$ & \multicolumn{1}{|c|}{ сочетаемость } & \multicolumn{1}{c|}{$\begin{array}{c}\text { Русский } \\
\text { эквивалент }\end{array}$} & \multicolumn{1}{c|}{ сочетаемость } \\
\hline \multirow{5}{*}{ smear } & themselves with clay & измазать & глиной \\
\cline { 2 - 4 } & tears, lipstick, mascara & размазать & слёзы, помаду, тушь для ресниц \\
\cline { 2 - 4 } & $\begin{array}{l}\text { children from head to toe } \\
\text { with tallow drippings }\end{array}$ & закапать & $\begin{array}{l}\text { детей свечным салом с ног } \\
\text { до головы }\end{array}$ \\
\hline \multirow{5}{*}{ smudge } & mascara, blood, sweat & размазать & тушь, пот, кровь по лицу \\
\cline { 2 - 5 } & face with oil & перепачкать & лицо маслом \\
\cline { 2 - 4 } & paper & пачкать & бумагу \\
\cline { 2 - 4 } & nose & испачкать & нос \\
\cline { 2 - 4 } & shirt sleeves with soot & выпачкать & рукава рубашки сажей \\
\hline
\end{tabular}

Разнообразие русских глаголов загрязнения настолько велико, а различие значений префиксальных производных одного и того же мотивирующего глагола настолько мало, что во многих случаях выбор переводчика кажется совершенно произвольным.

Вследствие развитости русского глагольного словообразования сходные явления можно наблюдать и при переводе с русского языка на французский и с французского на русский. Оттенки действия, которые в русском языке описывает приставочный глагол, во французских переводах передаются словосочетанием глагола с предлогом, наречием или дополнением; между тем, одному французскому глаголу соответствует целая серия русских глаголов с разными приставками или с одной приставкой и разными основами, например, arriver - npuбыть, приехать, прийти, прилететь, доехать, дойти, долететь [Гак 1976: 266-267].

\section{Литература}

Бабенко Л.Г. (ред.). Большой толковый словарь русских глаголов / Под ред. Л.Г. Бабенко. М.: АСТ-Пресс книга, 2007.

Гак В.Г. Сравнительная типология французского и русского языков. Л.: «Просвещение», 1976. 299 с.

Даль В.И. Толковый словарь живого великорусского языка. В четырех томах. М.: Русский язык, 2002.

Едремова Т. Ф. Новый словарь русского языка. Толково-образовательный. М. : Русский язык. 2000.

Крысин Л.П. Человек в зеркале русской разговорной речи (лексикографический аспект) // Słowo. Tekst. Chas XI. Szczecin; Greifswald, 2012. p. 539-547.

Маслов Ю. С. Вид и лексическое значение глагола в современном русском языке // Маслов Ю. С. Очерки по аспектологии. Л., 1984. С. 48-65.

Розина Р.И. Русская разговорная речь сквозь призму лексикографии и английского языка // Известия РАН. Серия лит. и языка, 2015, т. 74, № 4. С. 47-58. 
Ушаков Д.Н. (ред.). Толковый словарь русского языка, тт. 1-4 / Под ред. Д. Н. Ушакова. М., 1935-1940

Collins 2018 - Collins Thesaurus. Synonyms, Antonyms and Definitions. URL: https://www.collinsdictionary.com/dictionary/english-thesaurus (дата обращения: 20.06.2018).

\section{R. I. Rozina}

V.V. Vinogradov Russian Language Institute (Russian Academy of Sciences)

(Russia, Moscow)

rarozina@yandex.ru

\section{THE STRATEGY OF PREDICATES CONCEPTUALIZATION: VERBS OF SPOILING (DIRTYING) - MEANING, COMBINABILITY, ASPECTUAL BEHAVIOR}

The article is concerned with the comparison of Russian and English verbs of dirtying. The verbs under consideration are subdivided in either language into similar lexical groups, i.e. verbs of the result, of the way of dirtying and of the means of dirtying, yet the filling of corresponding groups is different. A much greater number of verbs of dirtying in Russian than in English, as well as the colloquial stylistic reference of the former in contrast to the neutrality of the latter, bring one to the conclusion that in English, in contrast to Russian, dirtying is not a communicatively relevant sense. The nature of meaning of Russian and English verbs of dirtying differs as well. Meanings of Russian verbs of dirtying are mostly results of semantic derivation, consisting in raising the presupposition of the basic meaning of verbs of various lexical classes to the level of assertion, whereas the meanings of the corresponding English verbs are non-derived. The analysis of the aspectual behavior of Russian verbs of each group reveals the difference between verbs of result on the one hand and both verbs of the way of dirtying and verbs of the means of dirtying on the other. The article addresses problems of translation as well. The wealth of verbal prefixal derivatives in Russian lacking in English results in difficulties one confronts while translating from Russian into English. This is why in English translations of Russian texts verbs of dirtying are often substituted with verbs of other lexical classes or omitted altogether.

Keywords: communicatively relevant senses, lexical class, aspectual behavior, verbs of dirtying, translation, Russian, English

\section{References}

Babenko G.L., ed. Bol'shoi tolkovyi slovar' russkikh glagolov [The big explanatory dictionary of Russian verbs]. Ed. By L. G. Babenko. Moscow, AST-Press kniga Publ., 2007.

Dal' V.I. Tolkovyi slovar' zhivogo velikorusskogo yazyka. V chetyrekh tomakh [The explanatory dictionary of the Great Russian language. In 4 vols.]. Moscow, Russkiy yazyk Publ., 2002. 
Efremova T.F. Novyy slovar' russkogo yazyka. Tolkovo-obrazovatel'nyi [The new dictionary of the Russian language. Explanatory-educational]. Moscow, Russkiy yazyk Publ., 2000.

Gak V. G. Sravnitel'naya tipologiya frantsuzskogo i russkogo yazykov [Comparative typology of French and Russian]. Leningrad, Prosveschenie Publ., 1976. 299 p.

Krysin L.P. [A human being in the mirror of Russian everyday speech (a lexicographical aspect.

Stowo. Tekst. Chas XI. Szczecin, Greifswald, 2012. P. 539-547. (In Russ.)

Maslov Yu.S. [The aspect and the lexical verb meaning in Modern Russian]. Maslov Yu.S. Ocherki po leksikologii [Lexicological sketches]. Leningrad, 1984. pp. 48-65. (In Russ.)

Rozina R.I. [Russian everyday speech through the prism of lexicography and English]. Izvestiya RAN. Seriya literatury i yazyka, 2015, no 4, pp. 47-58. (In Russ.)

Ushakov D. N., ed. Tolkovyi slovar' russkogo yazyka [The explanatory dictionary of the Russian language, vol, 1-4]. M, 1935-1940.

Collins Thesaurus. Synonyms, Antonyms and Definitions. URL: https://www.collinsdictionary.com/dictionary/english 